\title{
GROUND TRUTH SOIL MOISTURE ESTIMATION ALONG WITH MINIMAL DRIZZLING TIME
}

\author{
Vivek Chamoli ${ }^{1}$, Rishi Prakash ${ }^{2}$, Anurag Vidyarthi ${ }^{3}$, Shivangi Barthwal ${ }^{4}$ \\ 1,2,3,4 Department of Electronics \& Communication Engineering, Graphic Era (Deemed to be) University, Dehradun, Uttarakhand, \\ India
}

\begin{abstract}
The aim of this study was to determine the soil moisture along with minimal drizzling time using two methods using hot air convection oven (HA-CO) and microwave oven (MO) to find out the best method for estimation the soil moisture. The convection oven method was considered as the most accurate method to determine the soil moisture; hence, we utilized this method as source for assessing the results. The experiment was conducted in lab which was completely based on random 110 dry soil samples weight of approximately 100 gram from the bare land. In convection oven method we used $105{ }^{\circ} \mathrm{C}$ for 24 hours and in microwave oven method we used different thermal power $(180,360,540,720$ and 900 watt) for different time duration. The result based on the RMSE between soil moisture retrieval from hot air convection oven method and soil moisture retrieval from microwave oven method. 720 watt takes 15 minutes to dry the soil while 900 watt takes 8 minutes; both are gives approximately same results as convection oven method, which takes 24 Hours. Therefore for retrieval of soil moisture we can utilize the microwave oven method at 900 watt power. The low RMSE for 900 watt is $0.51 \%$ shows that the microwave oven method is most convenient, time saving and safe method for retrieval of soil moisture.
\end{abstract}

Keyword: Soil moisture, Conventional oven, Microwave oven, Minimal drizzling time, Moisture

\section{Introduction}

Water on the upper surface (usually 5 to $10 \mathrm{~cm}$ ) of the soil is classified as soil moisture. Measuring the soil moisture is an integral part of our irrigation field. A different application of soil moisture includes metrological, hydrological, agricultural systems or vegetation (Chamoli (2020), forestry, monitoring of flood and drought. Moisture is also significantly impacted by the engineering and service performance of highway components like soils, aggregates and stabilized materials.

Convention oven method also known as thermo gravimetric method was considered as the most accurate method for retrieval of soil moisture (Pandey (2019), (2020)). The main disadvantage of the conventional method is time required, i.e., 24 hours for drying the soil sample and it's also need more man power to monitoring the sample and conventional microwave temperature. A few investigations over numerous years have shown that there is an impressive of the potential for using the microwave drying method to make speedy and exact outcomes and various associations have created evaluation strategies for utilizing microwave oven drying. All things considered, questions still stay about specific worries with respect to the propriety of the microwave oven method. The particular target of this exploration is, to build up a system for quickly and definitely deciding soil moisture content. This is accomplished by assessing the exactness and testing lengths of drying soils with the standard microwave, and convection oven. The time needed to dry soil samples in the microwave oven at a specific power setting would depend on the amount of moisture present. However, in most practical cases, materials can be dried to a constant weight at a high power setting within less than 30 minutes (Tan (1992), Kevin (2002), Daod(2012), Chung (2008), Cormick (2015), Breckling(2016), Jalilian (2017)). The standard procedure with the conventional oven saves a considerable amount of time. Kevin (2002) stated that moisture contents could be obtained within 20 minutes instead of 24 hours. Johri (2020) stated that moisture contents could be obtained within 20 minutes at thermal power (800 $\mathrm{W})$. In some forms of soil, water is found in the mineral process in the form of hydroxyl molecules. Such hydroxyl groups do not usually belong to the water process and it can be removed during microwave drying method, but not in conventional oven drying method at $105^{\circ} \mathrm{C}$.

Sample size: The analysis of earlier experiments found that the microwave drying approach was used for a range of sample sizes. It is important to be remembered that by using the drying process, the sample size of the samples used tends to have an important effect on the time required to dry the samples successfully. Sample size varied from 10 grammes to 1 kilogramme in previous trials. Routledge and Sabey (1976) used the smallest samples, tested five of them with 10 grammes each, 20 samples with 50 grammes each. Testing was carried out. Carter and Bentley (1986) used a further analysis using comparatively limited sample sizes, while $1 \mathrm{~kg}$ samples were first used to determine the drying times for various soils, 20-30 grammes were used for most testings performed in the study. The sample sizes were between 50 and 300 grammes for most experiments. All the samples were taken with findings found to have very little variations in outcomes between different sample sizes of the same sample content in the analysis performed by Hagerty (1990b). The research proposed that sample measurements be kept as small as possible to minimize the chances of drying large specimens' 
exteri or layers; In the sample, especially when the substance is clay, but also when all the samples should be at least 100 grammes large.

Specimen container type: There are different choices for the vessel form that can be used in microwave drying to contain the soil sample. Metal containers are the only real exception from the container type to be used since they cannot be used in a microwave oven. Tared paper cups were used to carry specimes in an early analysis performed by Routledge and Sabey (1976).

Heating time: A variety of factors, including the soil type, sample size, microwave power and the moisture content of the soil to be checked, can influence the time taken to successfully search soil samples by microwave technique. Since the most important effect of other research on the heating period is related to the sample sizes, in these studies and corresponding sample sizes the time taken for dry samples needs to be checked to better select the right sample size to be used in this experiment.

The time needed to dry soil samples in the microwave oven at a specific power setting would depend on the amount of moisture present. However, in most practical cases, materials can be dried to a constant weight at a high power setting within less than 30 minutes (Tan (1992), Kevin (2002), Daod(2012), Chung (2008), Cormick (2015), Breckling(2016), Jalilian (2017)). The standard procedure with the conventional oven saves a considerable amount of time. Kevin (2002) stated that moisture contents could be obtained within 20 minutes instead of 24 hours. Johri (2020) stated that moisture contents could be obtained within 20 minutes at thermal power $(800$ $\mathrm{W})$. In some forms of soil, water is found in the mineral process in the form of hydroxyl molecules. Such hydroxyl groups do not usually belong to the water process and it can be removed during microwave drying method, but not in conventional oven drying method at $105^{\circ} \mathrm{C}$.

\section{Materials and Strategies}

\section{A. Comparison of convection oven and microwave oven to determine the soil moisture}

We used hot air convection oven (HA-CO) and microwave oven (MO) for the experiment as show in fig. 1 (a) and (b), respectively. 110 soil samples were randomly chosen from various parts of the playground of Graphic Era University. The soil samples were taken generally $4 \mathrm{~cm}$ to $6 \mathrm{~cm}$ depth from the field surface.

60 samples from 110 samples were used to compare the two methods. We added the water in the soil samples (100 gram each) in ratio of $10 \mathrm{ml}$ as show in fig. (c). 10 soil samples in Borosilicate Glass container were placed in the hot air conventional oven for 24 hours at $105^{\circ} \mathrm{C}$ temperature. Another 50 samples in Borosilicate Glass container were placed in the microwave oven for different time duration at different thermal power levels $(180,360,540,720$ and 900 watt Then, after the end of the period $(5,8,10,15,20,30,40,50,60$ and 70 minutes), soil samples were weighed using weigh machine with accuracy of 0.001 as show in fig. 1(d).

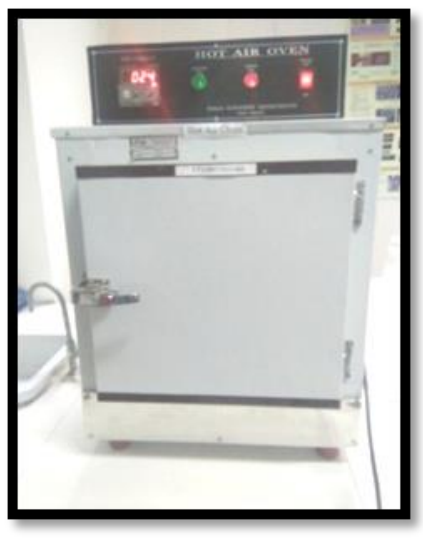

(a)

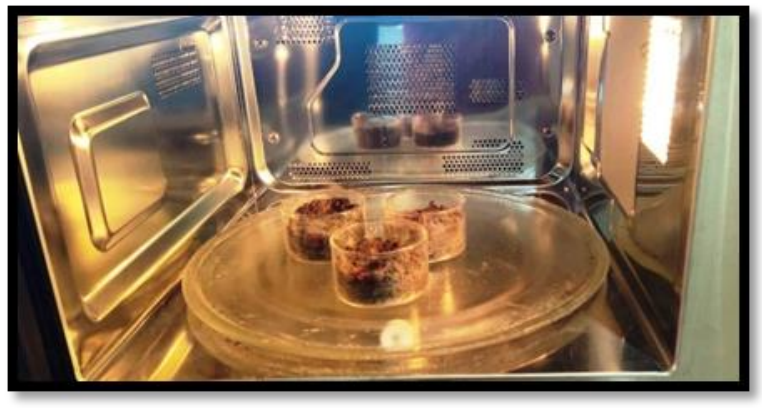

(b) 

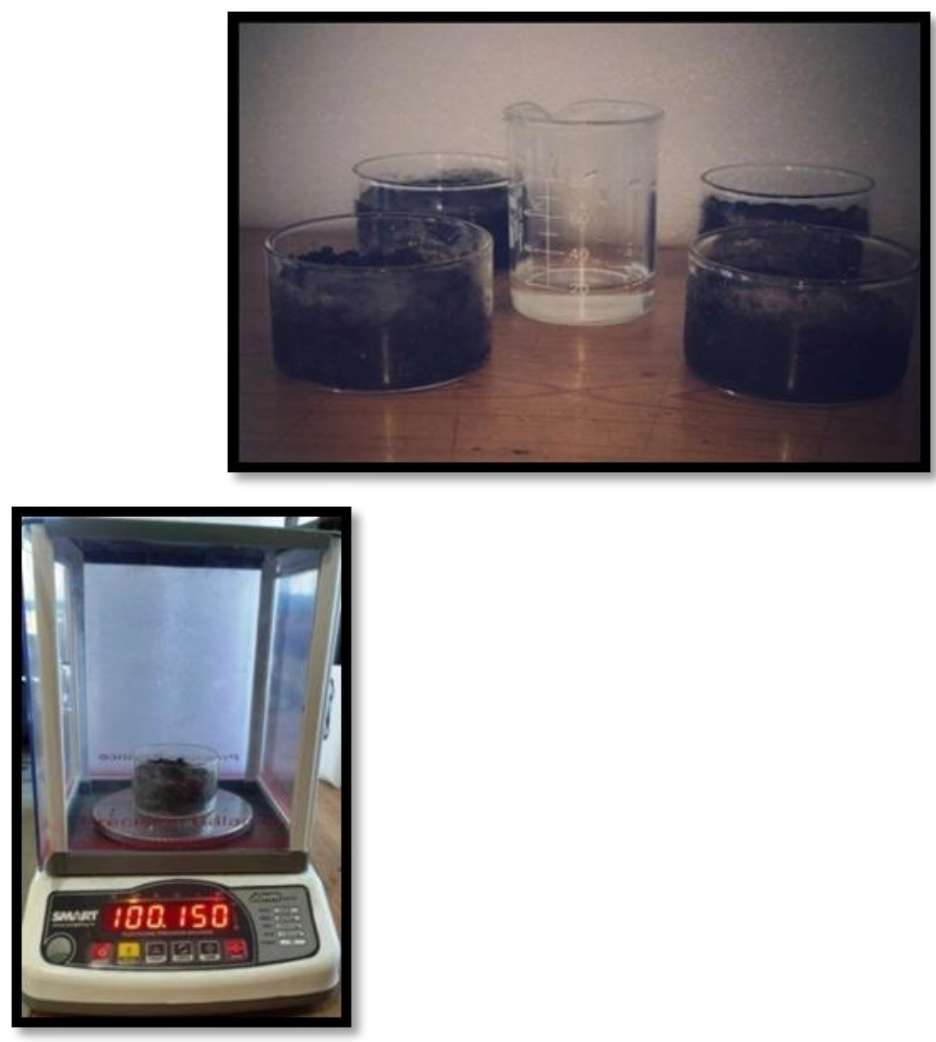

(c)

(d)

Figure. 1 (a) Hot Air Convection Oven (HA-CO), (b) Microwave Oven, (c) Soil samples \& beaker for measuring water to added in soil and (d) Weigh machine for weight the sample

where, Moisture is the percentage of soil moisture content,

The sample should be allowed to cool after each heating period in compliance with Australian standards. For each sample after each heating step, a one-minute cooling time was designed to remove any variability in tests due to different cooling. The percentage of soil moisture is assessed using Equation (1) in both methods [Chamoli (2017), (2020)].

Moisture $=O_{w e t}-O_{d r y} / O_{d r y} \times 100$

(1)
$O_{w e t} i s$ the weight of the soil with moisture content and $O_{d r y}$ is the weight of soil without any moisture content.

In comparison to the related drying periods, the moisture content from the microwave oven as shown in Fig. 2 is based on data collected during microwave drying. . In microwave, 180 watt power takes 70 minutes, 360 watt power takes 60 minutes, 540 watt power takes 30 minutes, 720 watt power takes 15 minutes and 900 watt power takes 8 minutes to dry the soil. All are gives approximately same results as convection oven method, which takes 24 Hours. 


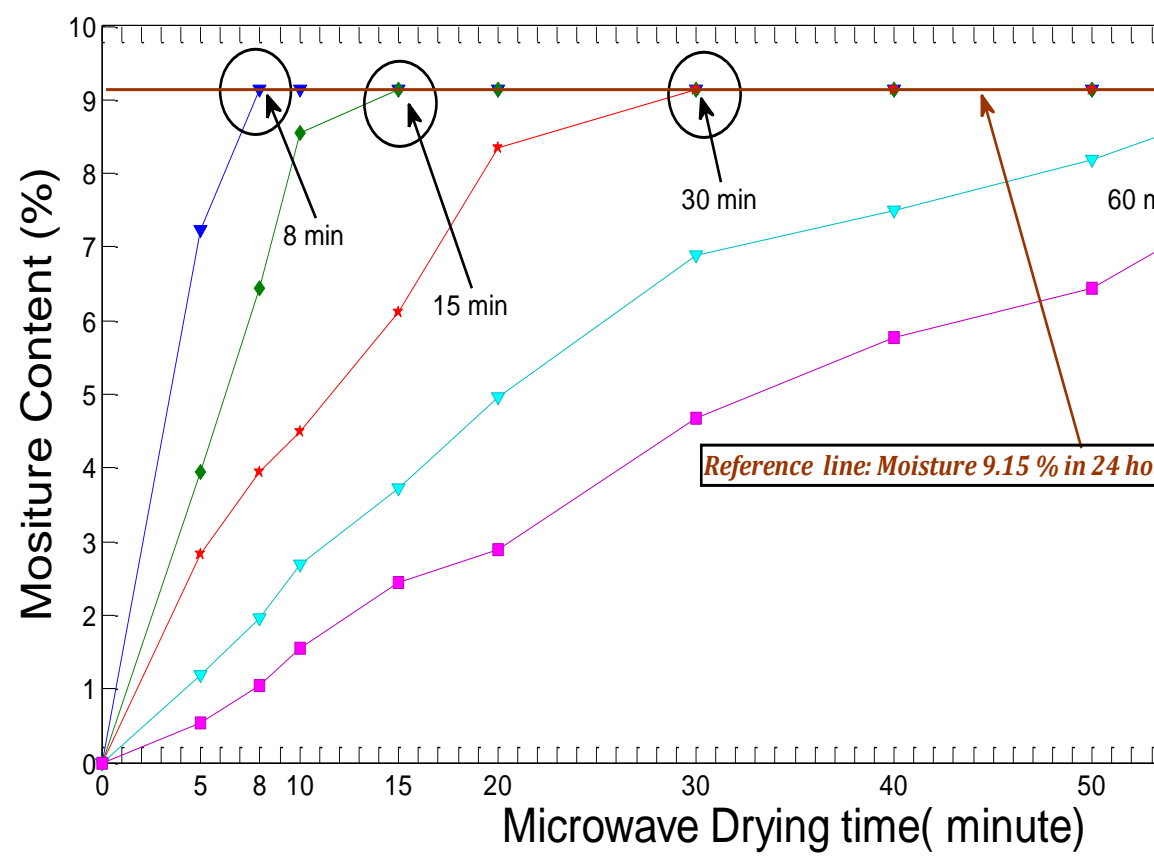

Figure. 2. Plot of moisture content using microwave oven versus microwave drying time (Batch -4)

Table 1 shows the comparison between hot air convection oven (HA-CO) and microwave oven (MO) with respective different thermal power and microwave drying time.

Table 1: Comparison of hot air convection oven (HA-CO) and microwave oven (MO)

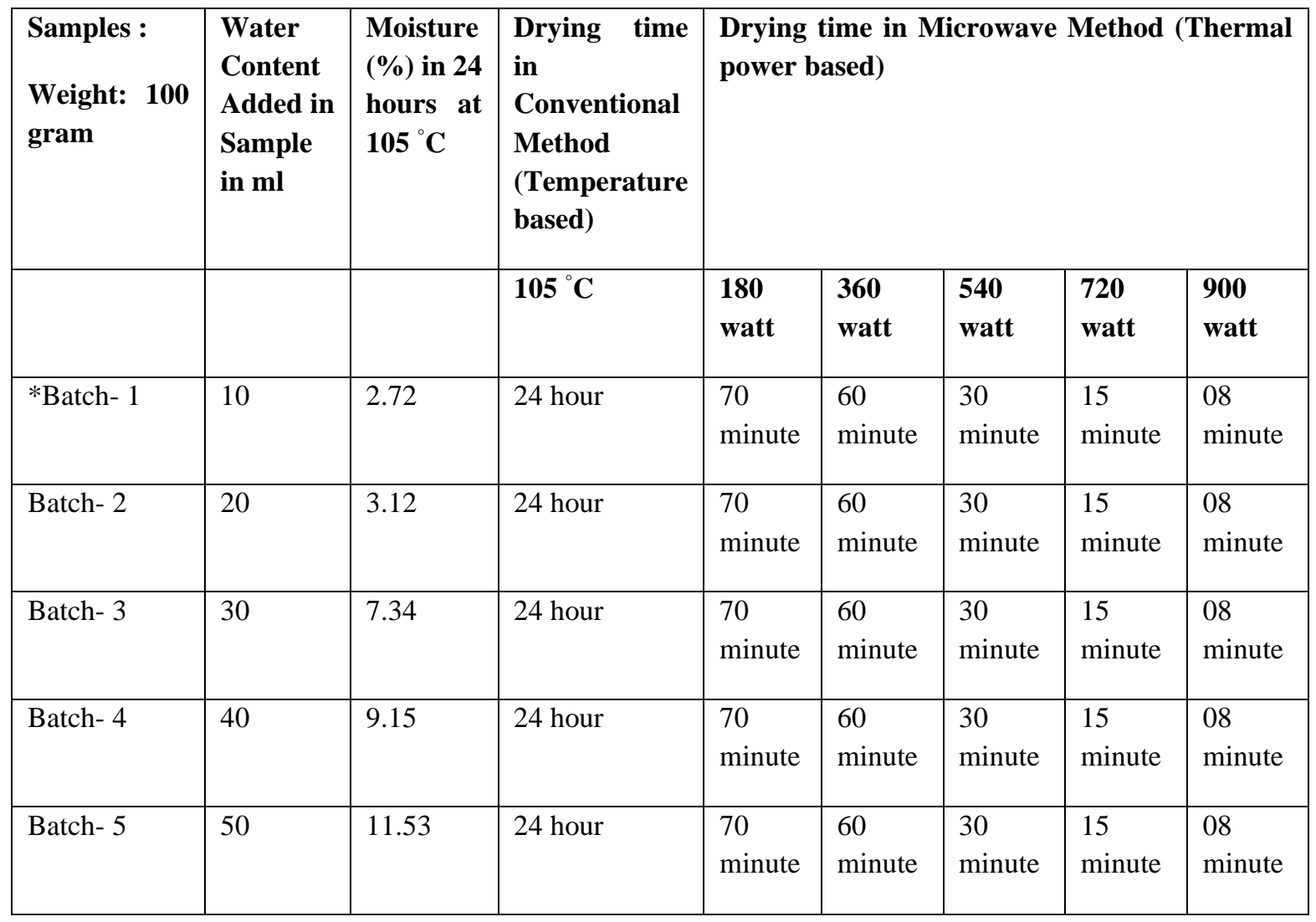




\begin{tabular}{|l|l|l|l|l|l|l|l|l|}
\hline Batch- 6 & 60 & 15.54 & 24 hour & $\begin{array}{l}70 \\
\text { minute }\end{array}$ & $\begin{array}{l}60 \\
\text { minute }\end{array}$ & $\begin{array}{l}30 \\
\text { minute }\end{array}$ & $\begin{array}{l}15 \\
\text { minute }\end{array}$ & $\begin{array}{l}08 \\
\text { minute }\end{array}$ \\
\hline Batch- & 70 & 17.22 & 24 hour & $\begin{array}{l}70 \\
\text { minute }\end{array}$ & $\begin{array}{l}60 \\
\text { minute }\end{array}$ & $\begin{array}{l}30 \\
\text { minute }\end{array}$ & $\begin{array}{l}15 \\
\text { minute }\end{array}$ & $\begin{array}{l}08 \\
\text { minute }\end{array}$ \\
\hline Batch- 8 & 80 & 19.41 & 24 hour & $\begin{array}{l}70 \\
\text { minute }\end{array}$ & $\begin{array}{l}60 \\
\text { minute }\end{array}$ & $\begin{array}{l}30 \\
\text { minute }\end{array}$ & $\begin{array}{l}15 \\
\text { minute }\end{array}$ & $\begin{array}{l}08 \\
\text { minute }\end{array}$ \\
\hline Batch-9 & 90 & 21.06 & 24 hour & $\begin{array}{l}70 \\
\text { minute }\end{array}$ & $\begin{array}{l}60 \\
\text { minute }\end{array}$ & $\begin{array}{l}30 \\
\text { minute }\end{array}$ & $\begin{array}{l}15 \\
\text { minute } \\
\text { minute }\end{array}$ \\
\hline Batch- 10 & 100 & 22.23 & 24 hour & $\begin{array}{l}70 \\
\text { minute }\end{array}$ & $\begin{array}{l}60 \\
\text { minute }\end{array}$ & $\begin{array}{l}30 \\
\text { minute }\end{array}$ & $\begin{array}{l}15 \\
\text { minute } \\
\text { minute }\end{array}$ \\
\hline
\end{tabular}

*Each Batch contain 1 sample for oven method and 5 sample for microwave method

Figure 3 demonstrates the drying process for both traditional ovens and microwave ovens. Figure 3 (a) indicates that the outer portion of the soil was first dried after that the inner part had been dried. Due to this phenomenon conventional oven takes much time to dry the soil. In microwave oven soil dried equally in both parts and takes less time as compare to conventional oven. The microwave oven reduced the conventional oven time of 24 Hours (1440 minutes) to 8 minutes. Therefore for retrieval of soil moisture we can utilize the microwave oven using thermal power instead of convention oven.

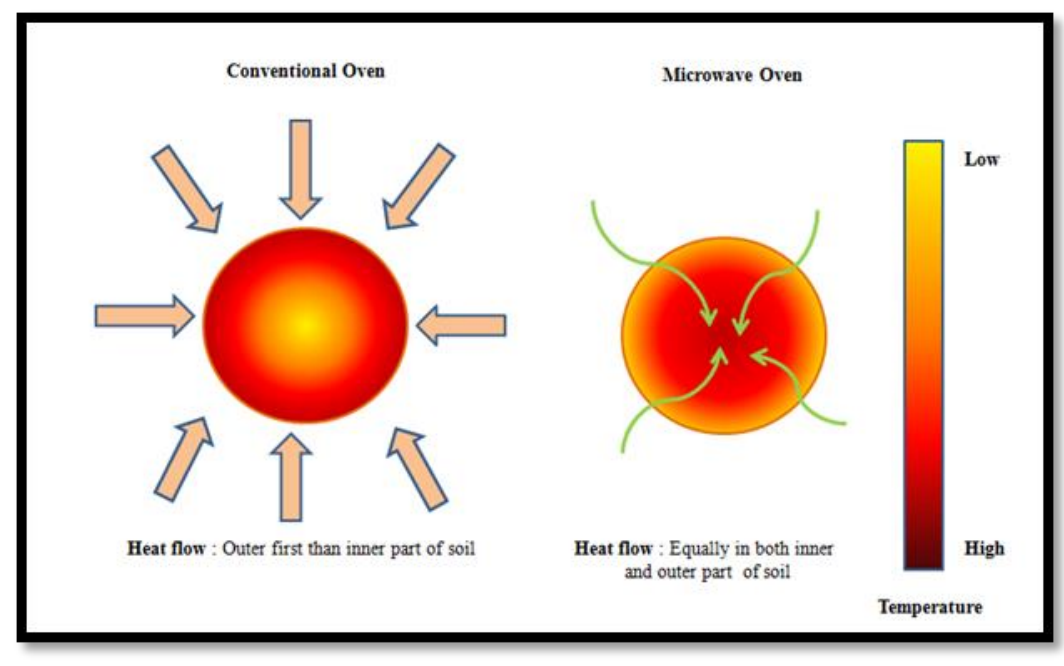

(a)

(b)

Figure. 3. Concept of drying method for (a) Conventional oven (b) Microwave oven

\section{Result and Validation for microwave method}

The study design was based on a randomized approach. The findings reveal that the short drizzle time ( 8 minutes) in the 900 watts microwave oven can effectively replace drying for 24 hours in a hot-air conventional oven. The drying output of a hot air oven $\left(105{ }^{\circ} \mathrm{C}\right.$ over 24 hours $)$ and a microwave oven (900 watt over 8 minutes) was contrasted to approximately $100 \mathrm{~g}$ of soils. In the hot air conventional oven 24 hours, 25 soil samples were placed at a temperature of $105^{\circ} \mathrm{C}$ in a Borosilicate Glass container. In the microwave oven for a power of 900 watts for 8 minutes, 25 other samples were placed. Fig. 4 shows comparison between estimation of moisture content using hot air convection oven (HA-CO) and microwave oven (MO).
To assessing the results of both methods we need to find the root mean square error (RMSE) Therefore, with the help of the equation ( ) we calculate the RMSE.

RMSE $=\sqrt{\sum_{i=1}^{n}\left(\left(C_{i}-M O_{i}\right)^{2} / n\right)}$

(2)

where $C O$ is the value of moisture content using hot air convection oven and $M O$ is the value of moisture content using microwave.

The low RMSE 0.51 in fig. 3 indicates that microwave oven process is most reliable, time-saving and secures approach for soil moisture estimation. 
Figure. 4. Comparison between estimation of moisture content using hot air convection oven (HA-CO) and microwave oven (MO).

\section{CONCULSION}

The present work was carried out with the objective of verifying the possibility of adopting the microwave oven in routine determinations of soil moisture. This study has shown that microwave ovens are an efficient means to determine the soil's fast moisture content as tests are carried out in a short period of time ( 8 minutes) with 900 watt thermal power and the acquired data is as accurate as the application of drying ovens. In some forms of soil, water is found in the mineral process in the form of hydroxyl molecules. Such hydroxyl groups do not usually belong to the water process and it can be removed during microwave drying method, but not in conventional oven drying method at $105^{\circ} \mathrm{C}$. The low RMSE $(0.51 \%)$ results indicate that the microwave oven process is the most effective way to measure soil moisture content and producing reliable results.

\section{References}

[1]. Breckling, Ed., V. V. Kramarenko , A. N Nikitenkov, V. Yu. Molokov, A. V. Shramok and G. P. Pozdeeva, (2016). Application of microwave method for moisture determination of organic and organic-mineral soils. IOP Conf. Series: Earth and Environmental Science, pp. 1-6.

[2]. Carter, M \& Bentley, S 1986, 'Practical guidelines for microwave drying of soils', Canadian Geotechnical Journal, vol. 23, n. 4, pp. 598-601.

[3]. Chamoli, V., Prakash, R., Vidyarthi, A., \& Ray, A. (2020, July). Analysis of NavIC Multipath Signal Sensitivity for Soil Moisture in Presence of Vegetation. In International Conference on Innovative Computing and Communications (pp. 353-364). Springer, Singapore.
[4]. Chamoli, V., Prakash, R., Vidyarthi, A., \& Ray, A (2020). Capability of XavIC, an Indian GNSS RMSE : 0.5 Constellation, for Retrieval of Surface Soil Moisture. Progress In Electromagnetics Research, 106, 255-270.

[5]. Chamoli, V Prakash, R., Vidyarthi, A., \& Ray, A. (2017, November). Sensitivity of NavIC signal for soil conoisture variation. In 2017 International Corference on Emerging Trends in Computing and Communication Technologies (ICETCCT) (pp. 14), IEEE

Chung, P.W., and Ho, T.Y. (2008). Study on the determination of moisture content of soils by microwave oven method. Geotechnical Engineering

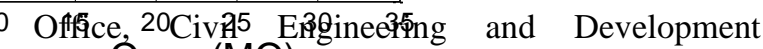
Microwaye Oyent. (MO)

[7]. Cormick J., A.( 2015).Comparing different heating methods for determination of moisture content in soils (dissertation).University of Southern Queensland.

[8]. Daod. H., (2012). Determination of Moisture Content and Liquid Limit of Foundations Soils, using Microwave Radiation, in the Different Locations of Sulaimani Governorate, Kurdistan Region-Iraq. International Journal of Civil and Environmental Engineering, Vol:6, No: 7.

[9]. Hagerty, DJ, Ullrich, RC \& Denton, MM 1990b, 'Microwave Drying of Soils', Geotechnical Testing Journal, vol. 13, n. 2, pp. 138-141.

[10]. Pandey, J., Chamoli, V., \& Prakash, R. (2020). A Review: Soil Moisture Estimation Using Different Techniques. In Intelligent Communication, Control and Devices (pp. 105-111). Springer, Singapore.

[11]. Pandey, J., Prakash, R., Ray, A., Chamoli, V., \& Vidyarthi, A. (2019, March). Study of GPS C/No ratio for retrieval of Surface Soil Moisture. In 2019 International Conference on Signal Processing and Communication (ICSC) (pp. 213-216). IEEE.

[12]. Jalilian J., S. S. Moghaddam and YTagizadeh,(2017). Accelerating Soil Moisture Determination with Microwave Oven. Journal of Chinese Soil and Water Conservation,pp.101-103.

[13]. Johri, A., Prakash, R., Vidyarthi, A., Chamoli, V., \& Bhardwaj, S. IoT-Based System to Measure Soil Moisture Using Soil Moisture Sensor, GPS Data Logging and Cloud Storage. In International Conference on Innovative Computing and Communications (pp. 679-688). Springer, Singapore.

[14]. Kevin J.G., "Rapid drying soils with microwave ovens." LTRC Project No. 99-3GT: Louisiana Transportation Research Center, 2002.

[15]. Routledge, DB \& Sabey, BR 1976, 'Use of a microwa

ISSN (Print): 2204-0595 
e oven for moisture determination in a soil science laboratory', Journal of Agronomic Education, vol. 5, pp. 25-27.

[16]. Tan. S. (1992).Effect of different water content, sample number, and soil type on determination of soil water using a home microwave oven. Soil Sci. Plant Nutr, 38 (2), pp.381-384. 